\title{
الفاشوش في حكم قراقوش الدوافع والأغراض.
}

م.م. رياض عبد الحسين راضي

جامعة واسط /كلية التربية

\section{المقدهة}

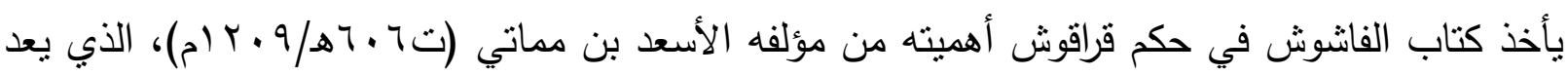

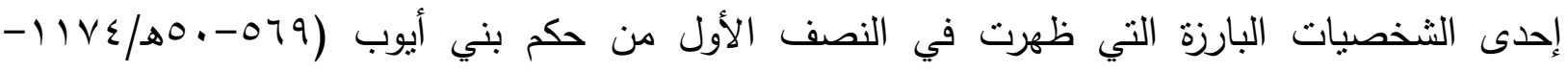

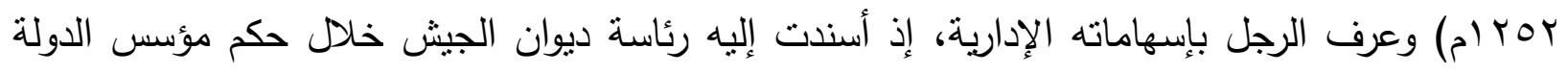

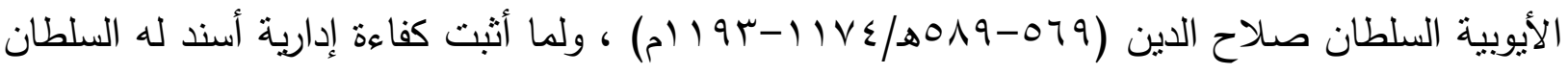

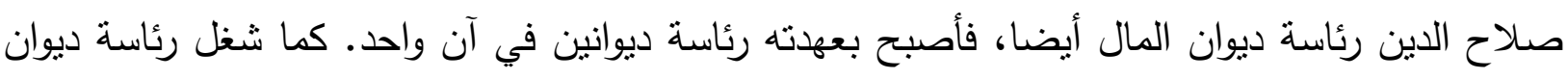

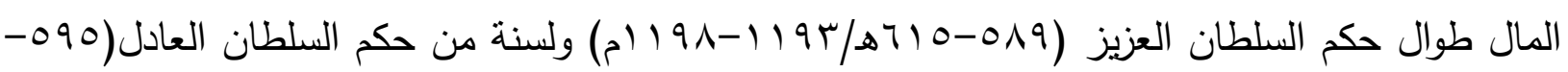
. (1) (1) (1)-1197/87)

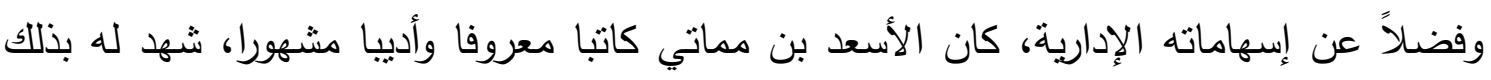

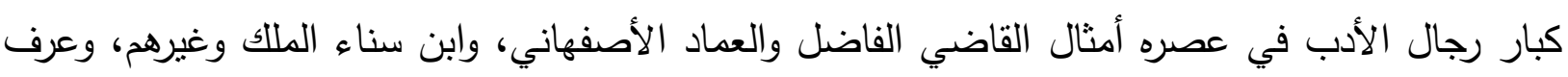

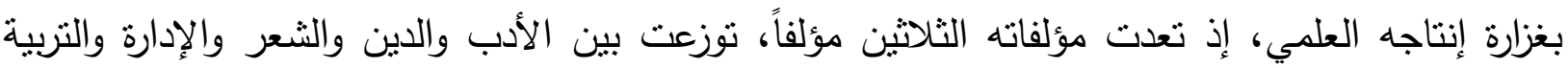

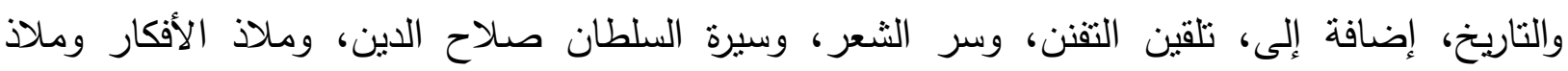

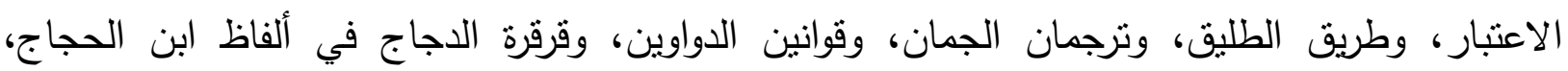

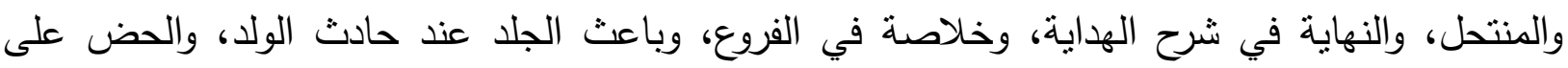

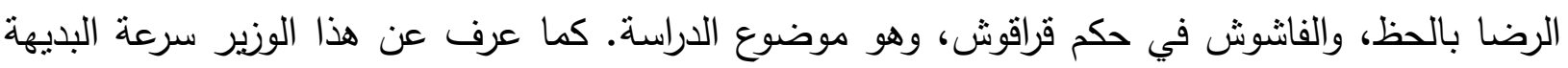

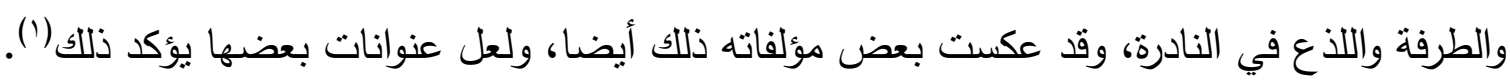

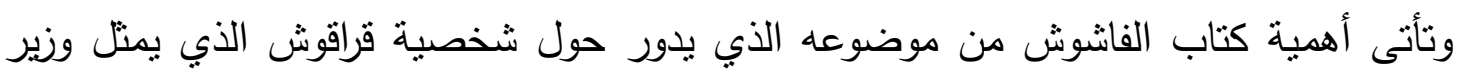

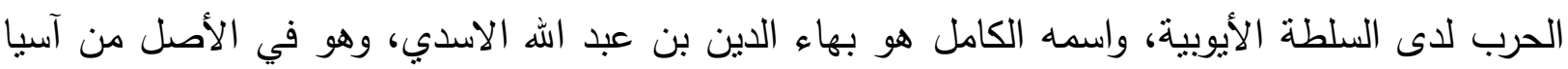

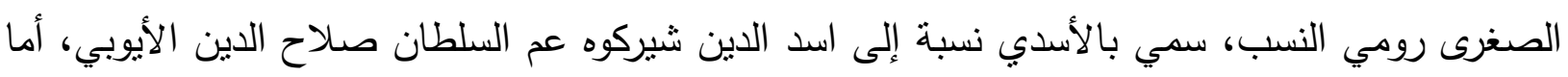

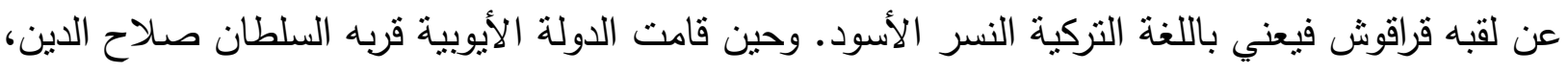

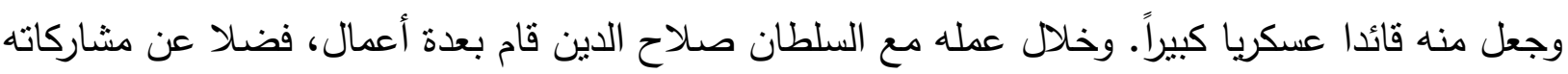

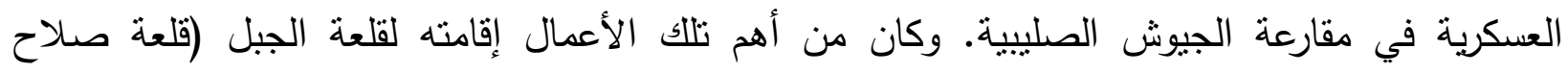

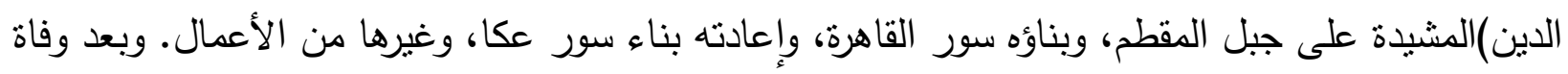

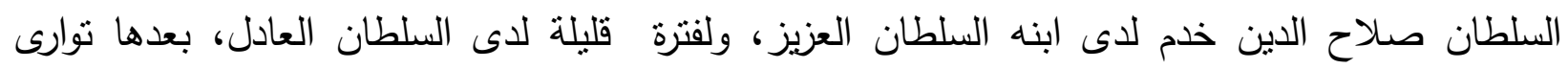

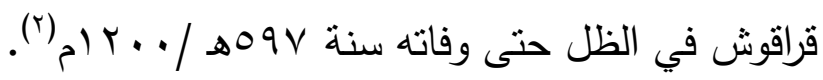


وتأني أهمية الفاشوش أيضا من الأسلوب الجذاب واللغة العامية التي كُتب بها، مما كان له اثر في إقبال العامة من القراء عليه، فضلا عن نجاح ابن مماتي في جعل شخصية قراقوش شخصية خيالية لكل الكل حاكم مهوس فيه بله وغفلة، مما كان له أثز في نفوس القراء، ولذللك كثر وصفه، وتعددت النوادر التي تروى عنه، والنسج على منواله، فكان للسيوطي ت(1) ابن مماتي نجح نجاحا هائلا في تثويه الثخصية بالثكل الذي جعل من قراقوش رمزاً لكل شخص مضحك

ومن هنا، فقد حظي كتاب الفاشوش بالعناية من قبل المهتمين بتاريخ الحقبة الأيوبية وأدبها، إذ إذ إنات درسوا الكتاب وموضوعه باهنمام، كالدراسة التي قدمها المستشرق كازنوفا ضمن تحقبقه لحكايات الفانشوش، باله ونشـرها تحت عنوان ( الطراز المنقوش في حكم السـلطان قراقوش )، وقد عـالج الدافع مـن وراء كتابـه الفاشوش، وكذللك دراسة الدكتور عبد اللطيف حمزة في كتابه (الفانوش في حكم قراقوش)، وما تقدم بـهـ فاروق سـعد في كتابه ( قراقوش ونوادره ) فضـلا عن المقال الذي كتبه الدكتور شوقي ضيف بعنوان (

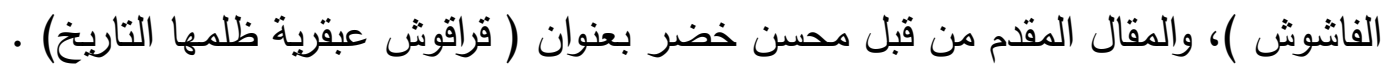
وعلى الرغم من فائدة هذه الدراسات في زيادة المعلومات عن كتاب الفانشوش، فإنها ظلّت بعيدة عن لفان بيان الدافع والغرض اللذين دفعا ابن مماتي لكتابة الفاشوش، ولم توضح ما الذي يريده الكاتب من ذلكات الكات

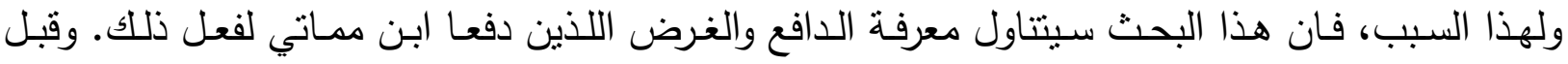
الخوض في ذلك كله لابد أن نتعرف على كتاب الفاشوش.

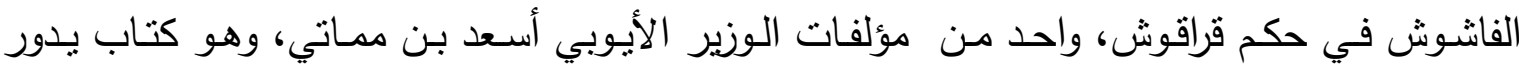
موضوعه- في الظاهر - حول الأمير بهاء الدين قراقوش أحد أمراء الحرب البارزين في الدولة الأيوبيـة، إذبان

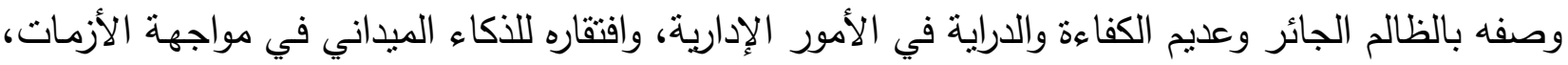

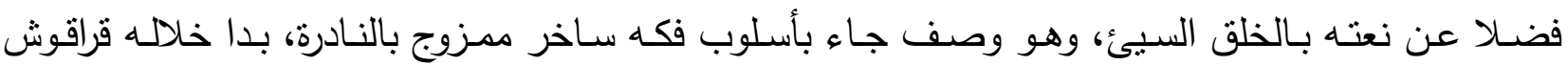

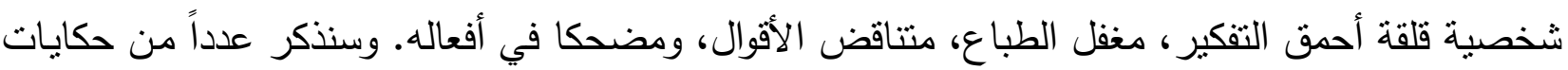
الفاشوش تجنباً للإطالة:

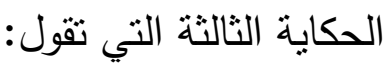

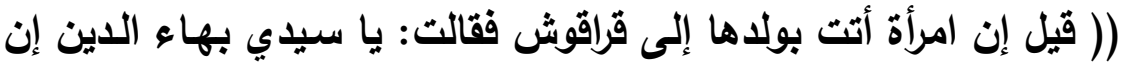

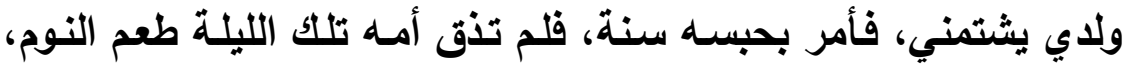

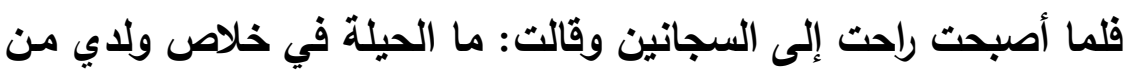

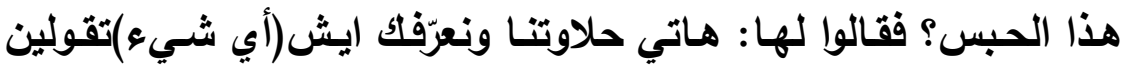

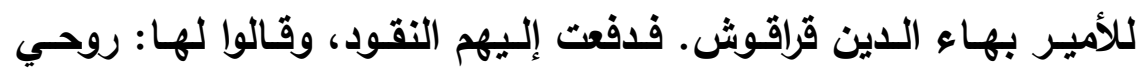

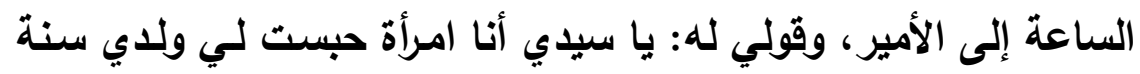

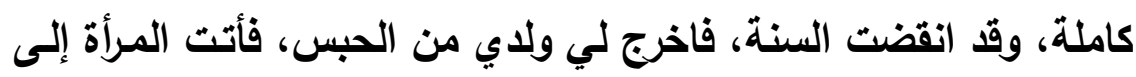


الأمير قراقوش، فقالت له ذلك فقال لها: روحي الان، فلا جدال في انه قـ

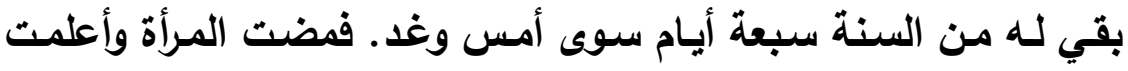

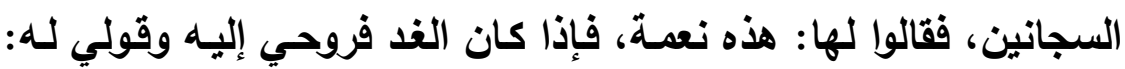
انقضت سبعة الأيـام! فأصبحت المرأة وجـاءت إلى قراقوش، فلمـا نظر إليها قال: يـا مرأة حتى تغرب الثمس! يـا غلام: إذا غريت الثـمس!

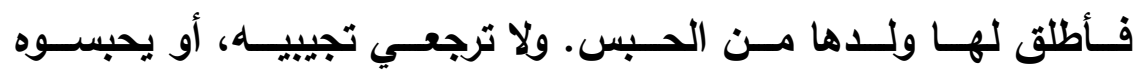

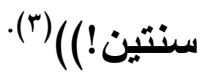

((قيل إن غلاما لقراقوش كان يشتغل عنده ركابدار( أي صاحب الركاب)،

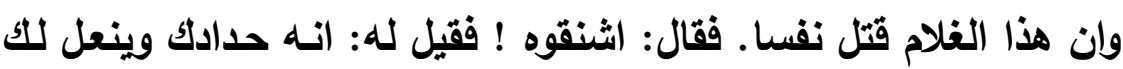
الفرس، فان شـقتته خسرته ولم تجد غيره. فنظر قراقوش ناحية بابه، فوجد رجلا قفاصا (أي صانع أقفاص)، فقال: ليس بهذا القفاص حاجة؛ فلما أتوه به قال: اثننقوا القفاص. وسيبوا الركابدار الحداد لكي ينعل لنا

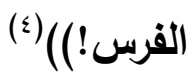

(توقف النيل بمصر أيامـا، فنظر قراقوش إلى جمـال السقايين، وهي تمشي عشرين عشرين، ففكر طويلا وقال:لو أخذت كل هذه الجمال من

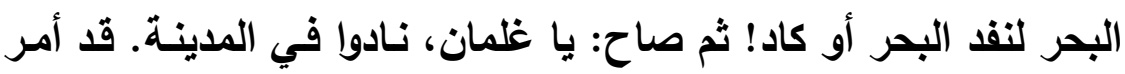
بهاء الدين قراقوش لا يملي أحد من البحر ألا جملا واحدا. ففعلوا ذلك.

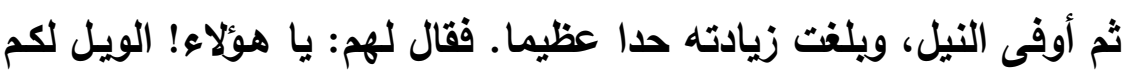
أن عدمتموني. فكيف رأيتم رأيي عليكم ؟ ما هو ألا أي مبارك!)()(ه).

(أ(كي أن جماعة من الفلاحين جاعوا إلى قراقوش، وشكوا إليه من خراج القطن، وقالوا لـه: يـا مولانـا السـلطان، البرد شـوش على القـى القطن هذه السنة، وأنت تفرج عنا وتسامحنا من بعض المـال فكان من جوابـه لهم

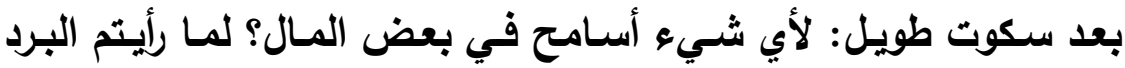

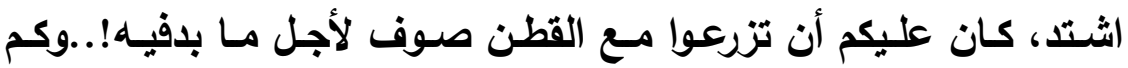

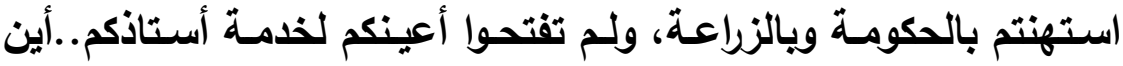

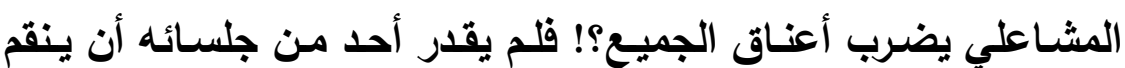

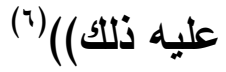




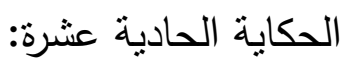

((حكي أن قراقوش جاءه شيخ وصبي أمرد، كل منهما يقول:يا مولاي

داري! وعند ذلك نظر قراقوش إلى الصبي وقال: معك كتاب يشهد للك؟ قال: لا قال الأمير بهاء الدين: فالدار إذن للثيخ الكبير · يا صبي ادفع

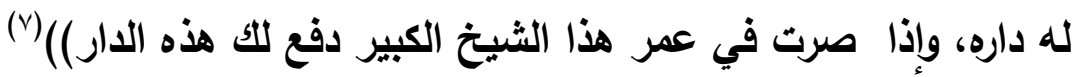

الحكاية الخامسة عشرة:

(انه -أي قراقوش - كان في كل سنة يتصدق بمال جزيل، فلمـا انتهت الصدقة اشتكت إليه امرأة أن زوجها مات ولا كفن له فقال : أمسا الصدقة بتاع هذه السنة فقرغت. ولكن إذا جاءت السنـة آلاتية فتعالي نـأمر لك

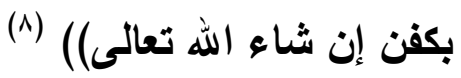

بعد هذا العرض لمجموعة من حكايات الفاشوش يبرز السؤال الآتي:لماذا كتب ابن مماتي الفاشوش؟ يقول ابن مماتي عن الدافع وراء كتابته للفاشوش هو :

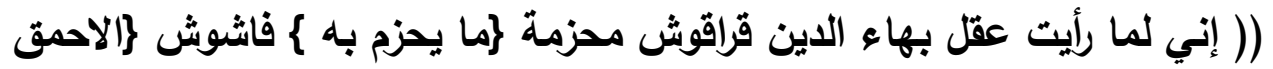

\{ وقد اتلف الأمة، والله يكشف عنهم كل غمة، لا يقتدي بعالم، ولا يعرف المظلوم من الظالم، الشكية عنده لمن سبق، ولا يهتدي لمن صدق، ولا يقدر أحد عظم منزلته على أن يرد كلمته، ويشتاط أشتياط الثيطان، ويحكم حكما مـا أنزل الله بـه من سلطان، صنفت هذا الكتاب لصلاح الدين، عسى أن يريح منه المسلمين )(a) (9) وهو قول يفهم منهـ أن الثـعور بالوطنية والمسؤولية تجاه الدولة والرعيـة كان وراء تصدي ابن ممـاتي لذلك الأمير، لأنه يرى أن شخصية قراقوش القلقة كانت تقود الدولة إلى خراب، لاسيما وأنها تمر بظرف سياسي وعسكري حرج، إذ إنها كانت تخوض الصراع ضد الصليبيين •

وبعد استقراء المدة التي عـاش أحداثها بهاء الدين قراقوش، وجد أن الصـورة التي عكسها الفاشـش تتقاطع تماما مـع ما سجله التاريخ عن قراقوش، فهي تتاقض صورة الأخير لدى السلطة الأيوبية ورجالاتها، وتخـالف تمامـا الصـورة التي رســها المؤرخـون عن قراقوش، وتتضـارب مـع الرؤيسة الصـليبية تجـاه الرجل، وبخاصة لو وضعنا في الاعتبار أن الصليبيين هم أعداء للدولة الأيوبية التي يعد قراقوش واحدا من أمرائها الحربيين. وفيما يخص مكانته لدى سلاطينه، كان قراقوش يتمتع بمكانة كبيرة وثقة عالية لايهم، بل كان ضلعا في المنلث الإداري الذي ارتكزت عليه الدولة عند قيامها، والذي مثل ضـلعيه الآخرين القاضي الفاضل ت

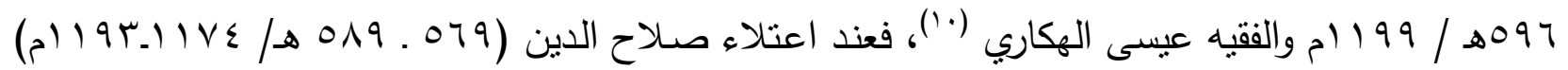
عرش السلطنة جعل قراقوش أمينا على القصر الفاطمي المليء بالجواهر والتحف الثمينة وأثياء أخرى لا تقدر

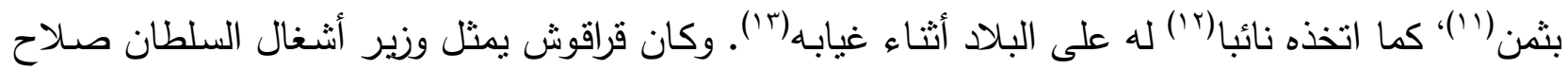
الدين، إذ قام خـلال تسلمه هذا المنصب بثلاثة أعمال شهد التاريخ بأهميتها وهي بناء قلعة الجبل، وتشييد 
سور القاهرة، وترميم سور عكا ، فضـلا عن أعمال كثيرة أخرى(ء)". وللمكانة العالية التي يكنها لله السلطان صـلاح الدين نراه يفتديه بعشرة آلاف دينار ، حين وقع أسيرا لدى الصليبيين أثتاء أعادتهم مدينـة عكا سنة

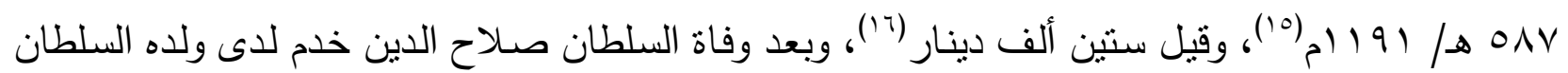

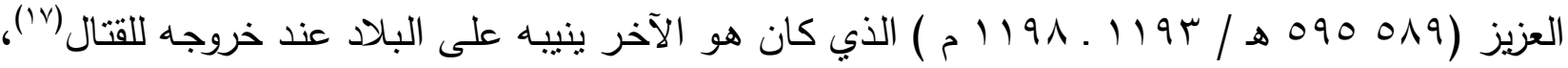
وهو أمر يدل على المكانة والثقة العالية التي يكنها السلطان لقراقوش. وبالمقابل كان الأخير أهلا لهذه الثقة وللمكانة الرفيعة، وأمينا في خدمة السلطان، وانعكس ذلك من خلال إحباطه المؤامرة التي حاك خيوطها الملك

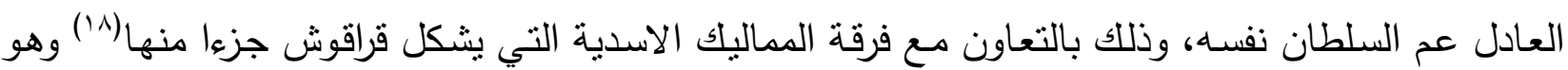
أمر يعكس إخلاص قراقوش الكبير للدولة الأيوبية المتمنلة بالسلطان العزيز • ونظراً لمـا يتمتع بـه من مزايـا خاصـة ، وقدرات عاليـة جعلت السلطان العزيز يسند إليهه منصب

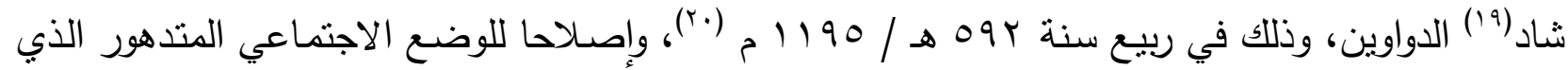
تخلل حكم العزيز رأى الأخير أن يسند منصب رئاسـة ديوان المظالم إلى قراقوش، لما رأى فيـه من كفاءة وعدالة في الأداء(اr)، وللتقة العالية أناط بـه السلطان العزبز كي يكون وصيا على ابنه المنصور (ه0ه . . 79 9 هـ / 1911 ـ 199 ( (م)، لكن ظروفا استجدت بعد وفاة السلطان العزيز جعلت من الأفضل ابن السلطان صلاح الدين وصيا بدلا من قراقوش(rr)، وعلى الرغم من هذا الأجراء فلم يبد قراقوش أي اعتراض على ذلك

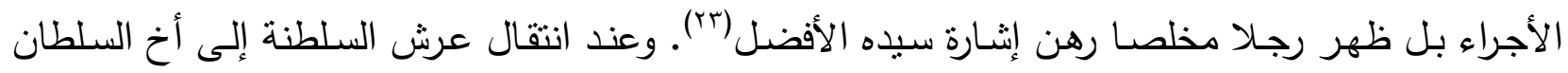

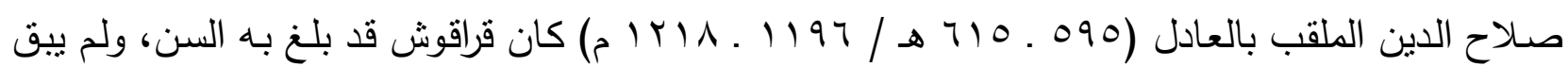
من عمره إلا اشهر قليلة أبى أن يقضيها في الراحة، بل قام خلالها بأعمال عمرانية شهد له التاريخ بها(؟؟). أمسا عن مكانته بين رجالات الدولة، فالقاضي الفاضل الذي شغل منصب رئيس ديوان الإنشاء و تمتع بمكانة مرموقة في الدولة الأيوبية، كان يمدح الأمير قراقوش في كل رسالة يمر ذكره بها(ror)، فضسلا عن انها قاطع الاجتماع الذي عقد من اجل البت في أمر أبعاد قراقوش عن وصاية الملك المنصور ، وحين طلب رأيه في ذللك امتتع (بr) مدللا بذلك على مدى ما يكنه لقراقوش من احترام وما يحظى لديه من مكانة عالية، أما

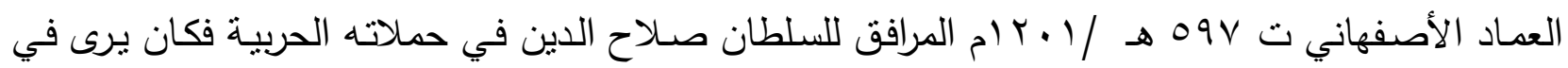
قراقوش رجلا عالي الهمة، لا يقارع ذا المواقف المعروفة والأعمال الجليلة(rV)، ويشاطره في رأيه هذا ابن شداد

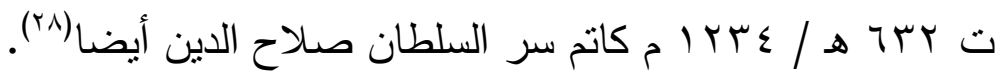
وفيما يتعلق بمكانته لدى المؤرخين فقد كان قراقوش يحظى لديهح بمنزلة لا تقل أهميتها عن السابقة، إذ انه كان يوصف بالرجل صاحب الهمة، والثجاعة، ووقار العقل، وجمال النية فضلا عن انهم كانوا يرون في وصف ابن مماتي لقراقوش زيفا لا أساس لله من الصحة(9"). أما صورة قراقوش لدى الصليبيين فقد وصفوا شخصيته بأنها شخصية محاربة، روحها غريبة كثيرا ما أدهثتهم وأثنارت إعجابهح لما تحمله من مهارة وقدرة وجلد وعزيمة حتى انهم نظروا إليه على انه جندي وقديس

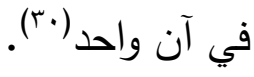


إن هذا الاستقراء يقود إلى ثلاثة احتمالات ملحة هي:

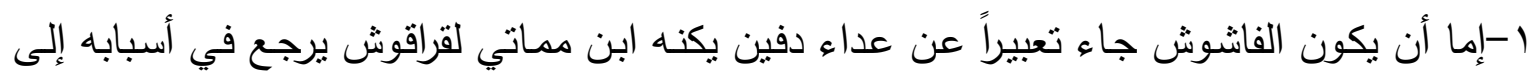
خصومة سياسية شخصية يتداخل فيها الحسد والغيرة والمادة . r-أو أن يكون تعبيرا عن حقد ابن مماتي على الدولة الأيوبية .

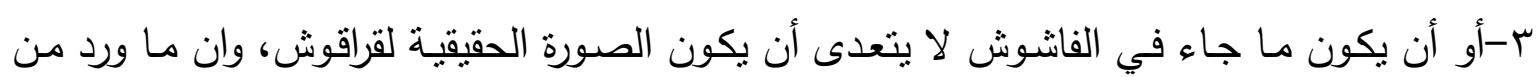
صور أخرى عن قراقوش ما هي إلا صور عكستها مرايا محدبة.

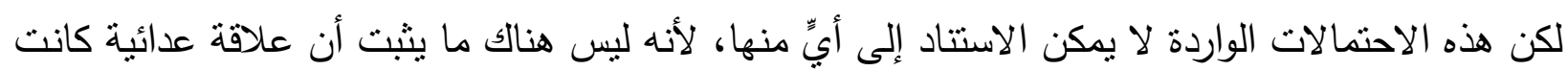

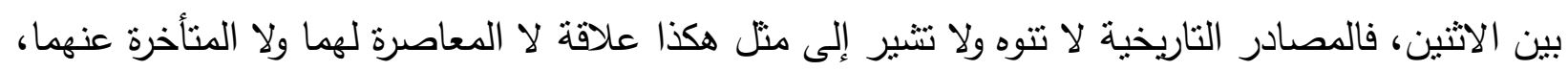
ثم إن ابن مماتي لم يشر في شعره الساخر الذي وصل إلينا لا من قريب ولا من بعيد إلى شخصية قراقوش.

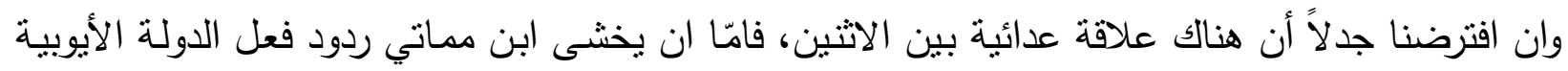

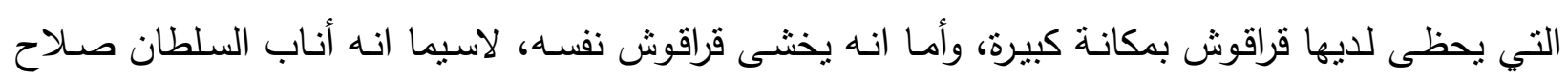
الدين عن البلاد عدة مرات والنائب له صلاحيات واسعة وسلطة كبيرة، منها عزل الموظفين ومعاقبتهم.

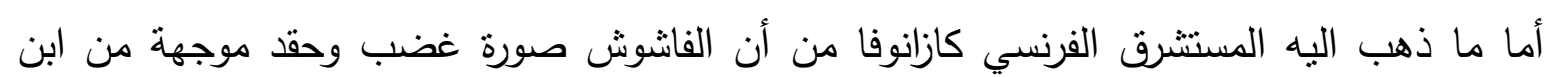

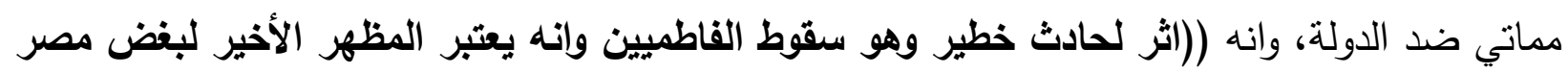
وأهلها لكل فاتح لبلادهم وهو بغض أيقظه في نفوسهم انهيار الخلافة الفاطمية وقيام الدولة الأيوبية التي ولئي

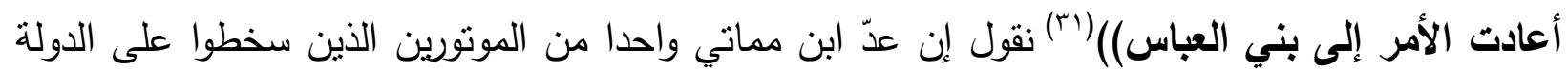

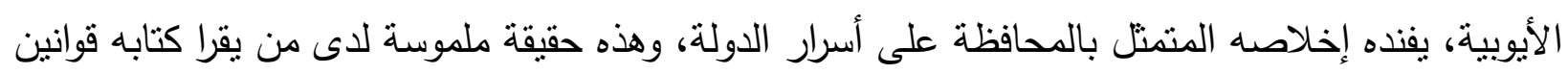

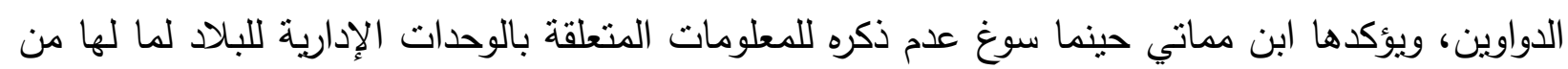

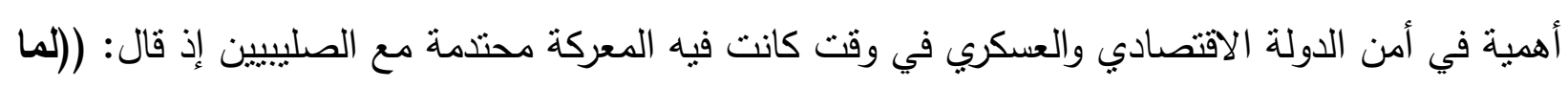

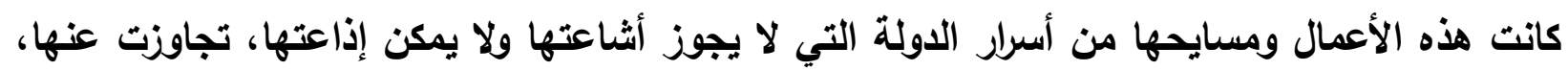

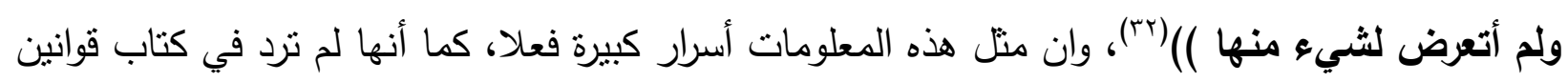

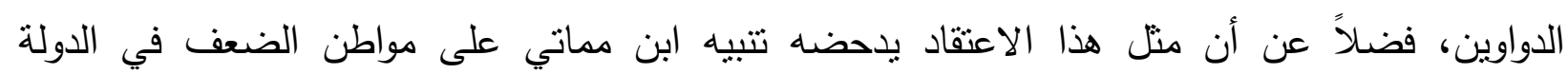

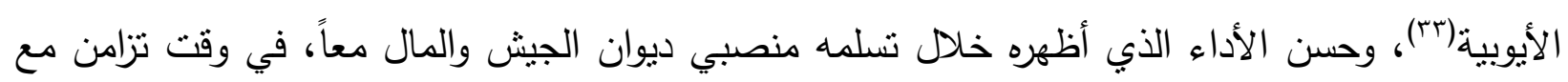

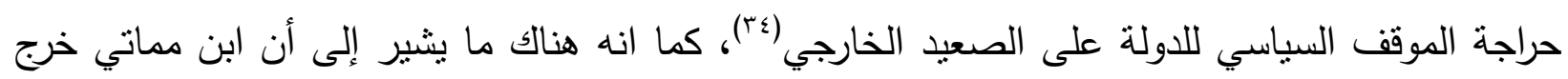

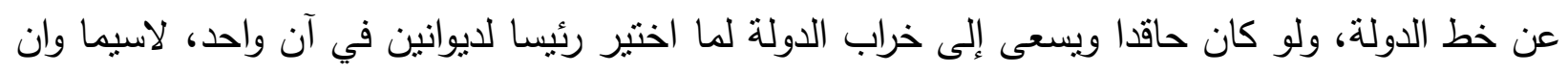

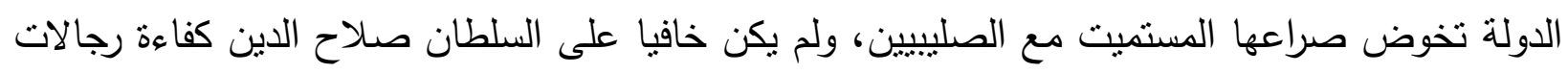

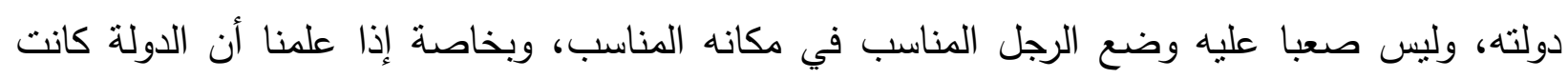

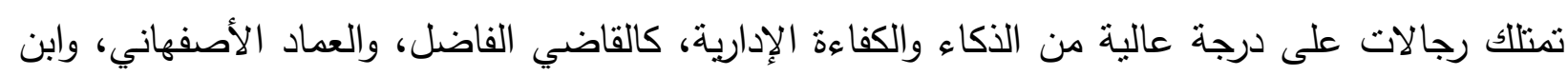

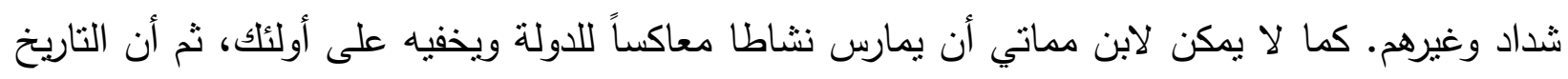
لم يسجل أية خيانة لأسرة ابن مماتي تجاه الدولة. 
وإذا كان الأستاذ كازونوفا يقصد أن ابن مماتي أراد أن يصور في الفاثـوش سخط أهل مصر على الإنى

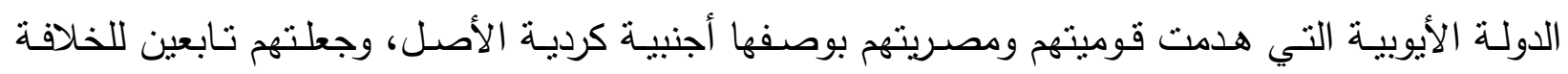

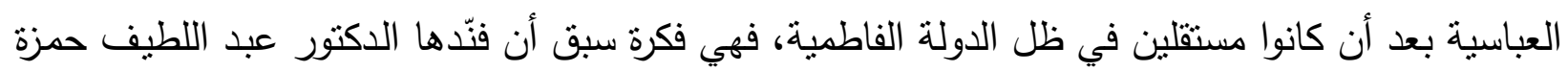
في معرض رده على ذلك، إذ ذكر أن أهل مصر نظروا إلى السلطان صلاح الدين على انه بطل الدهل المسلمين وصاحب الفضل الأكبر في إنقاذهم من أيدي الصليبيين، في وقت كانت الخلافة العباسية في بغداد والخلافة الفاطمية في مصر عاجزة عن درء الخطر الصليبي عن نفسها وعن الإسـام، زد على ذلك الك أن السلطان

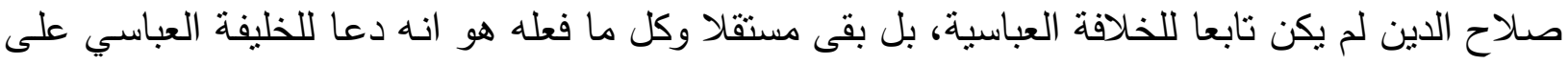

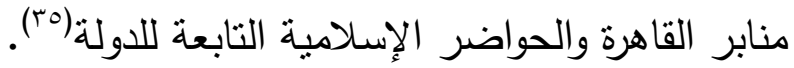

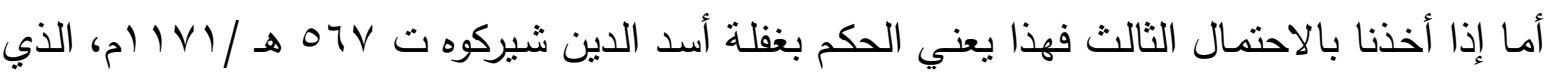

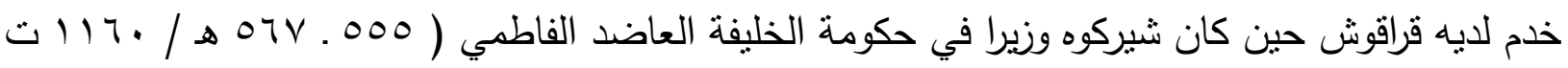
(IV)

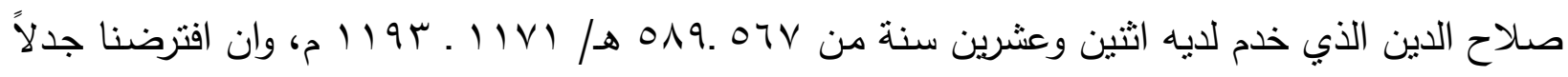

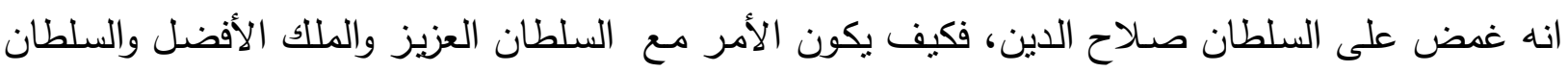

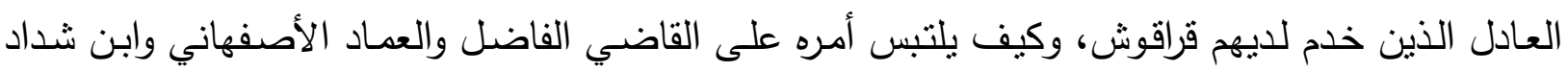
ويتجاوز تمحيصات المؤرخين؟ وان كان قراقوش هكذا فما الذي يجعل الأعداء الصليبيين يرونه عكس ما واليا

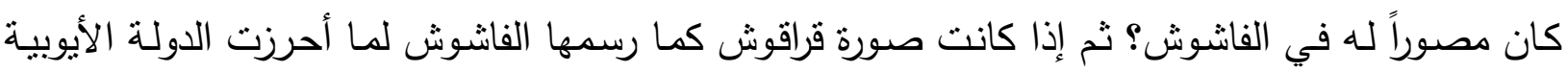

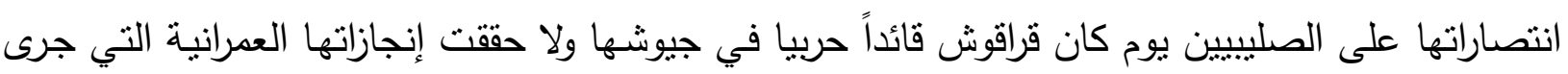
بعضها تحت الإشراف المباشر لقراقوش نفسه. إذن الفاشوش لم يمثل صورة عداء بين ابن مماتي وقراقوش، ولم يكن صورة حاقد موتور على الدولة

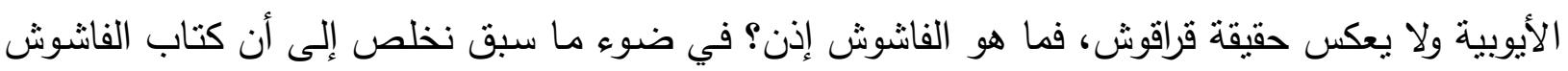

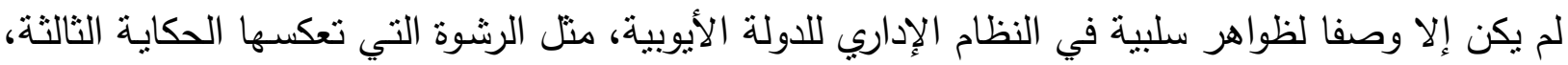

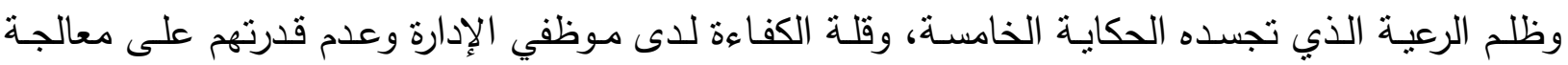

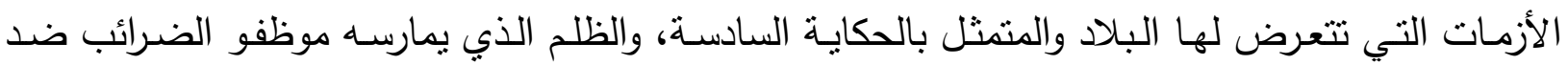

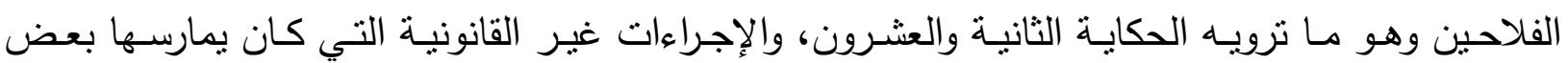

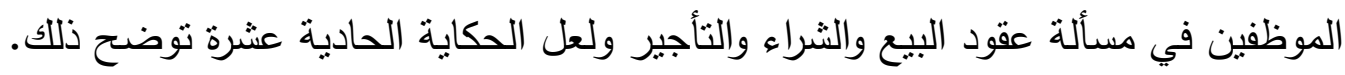

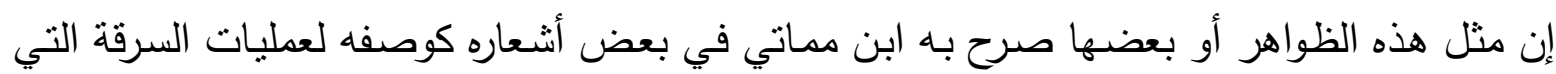

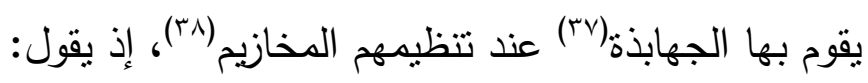
مخازيم تضمنت المخازي

\section{يجوز فعلها ما لا يـجوز}




\section{لصوص يرفعون إلى \\ لصوص حسابهم وينهم رموز (ra) \\ وفي مناسبة أخرى يقول: \\ مخازيم عملن بغير ميم

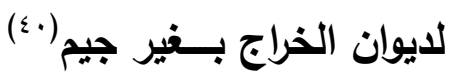

بيد انه أعلن عن هذه الظواهر بصراحة اكثر في كتابه قوانين الدواوين الذي ألفه في زمن العزيز ، وكان يهدف من ورائه الى معالجة تللك الظواهر لاسيما المتعلقة بموظفي الدولة، فقد ذكر فيه الرشوة، وقله الكفاءة

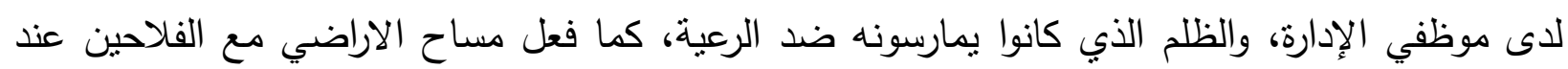

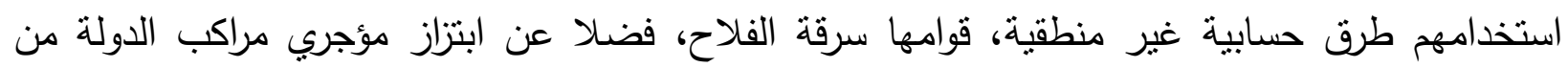
الرعية من قبل الموظفين المسؤولين عن تأجير تلاك المراكب، والإجراءات غير فئه القانونية التي كان يمارسها

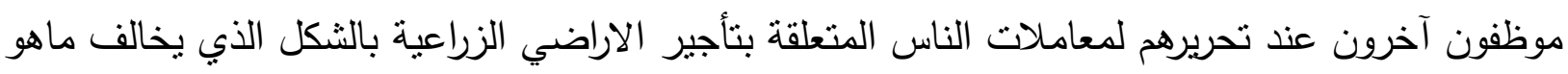
متبع رسمياً، فضلا عن سوء تصرف بعض الموظفين باموال الدولة واهمالهم لمواردها وسوء ادارة مؤسساتها،

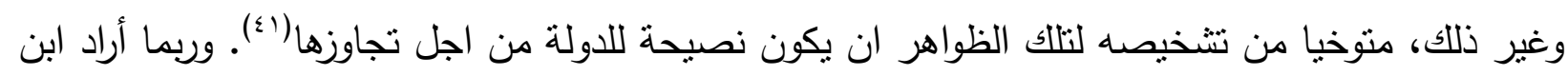

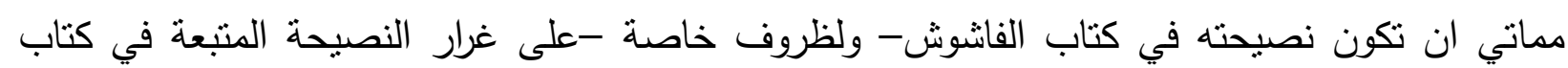

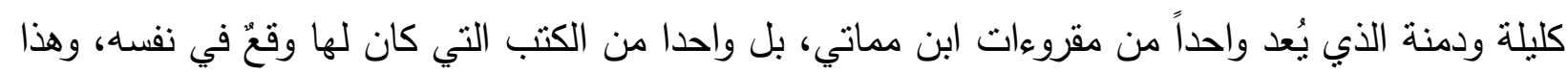

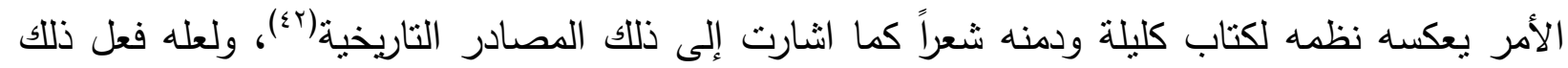
وفقاً للحكمة التي تقول (اخبر السلطان بعيبه من غير ان تواجهه). وبذلك فابن مماتي لم يكن يقصد

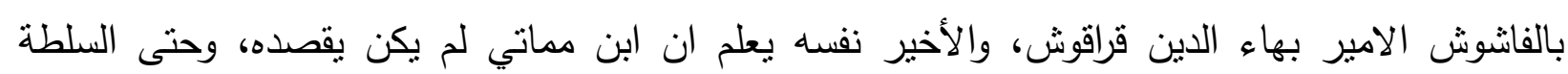

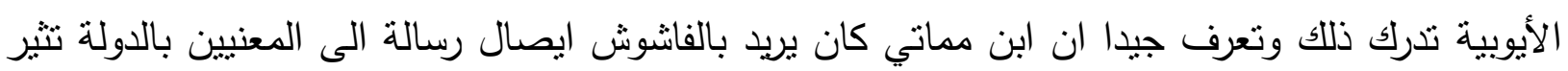

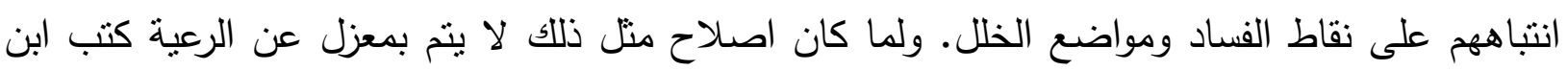

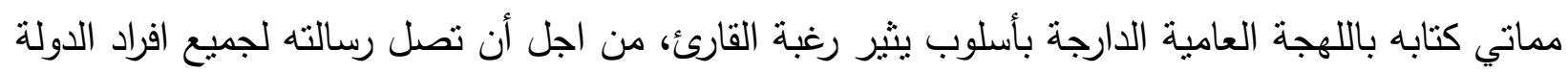
اداريين ورعية.

يدور هذا البحث حول كتاب (الفاشوش في حكم قراقوش ) المؤلف من قبل الوزير الأيوبي اسعد بن

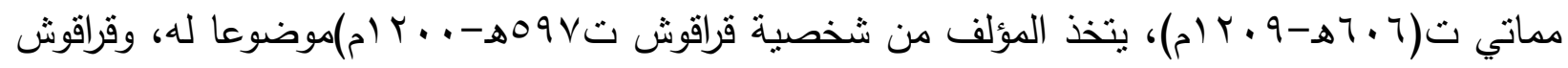

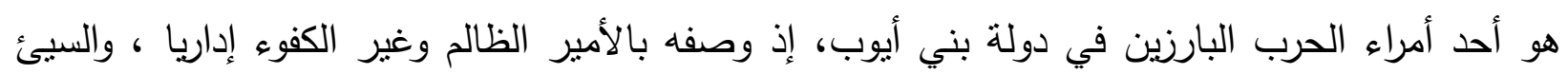

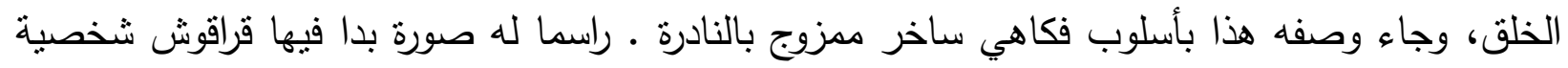

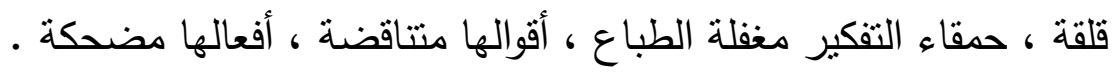


جاء هذا البحث ليجيب على أسئلة ملحة تتعلق بالكتاب وموضوعه وهي:ما هي الدوافع والأغراض هاض التي دفعت ابن مماتي لكاتبة هذا الكتاب ؟ ولماذا اتخذ من قراقوش موضوعا له ؟وهل كانت شخصية

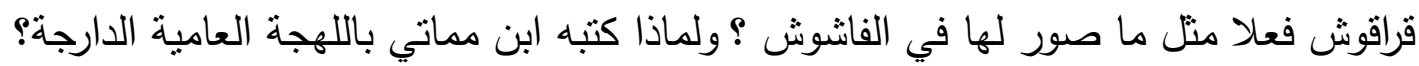
(1) عن ابن مماتي ينظر : رياض عبد الحسين راضي البدراوي،اسعد بن مماتي وكتابه قوانين الدواوين، رسالة ماجستير غير

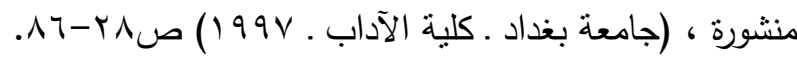

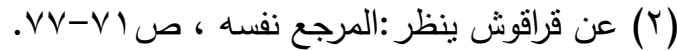

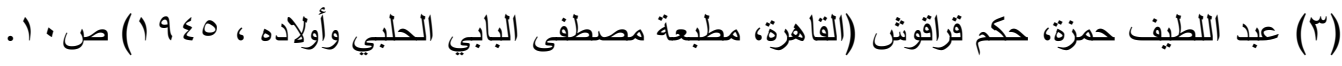

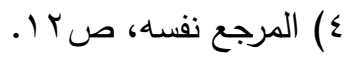

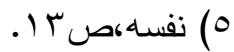

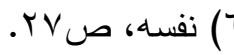
. I I (V)

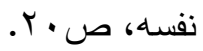

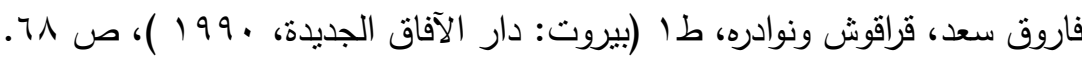

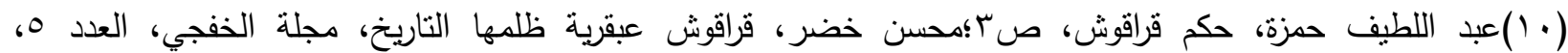

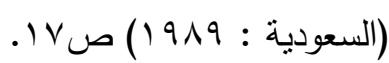

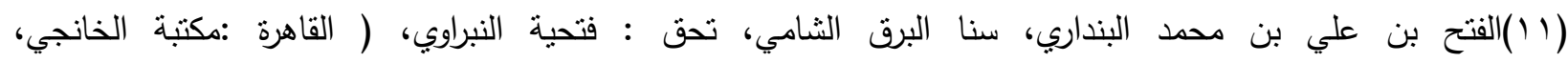

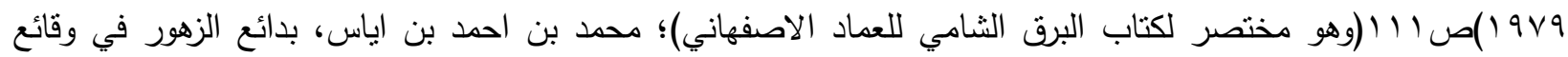

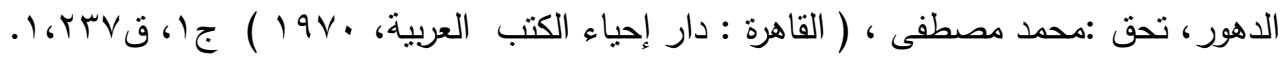

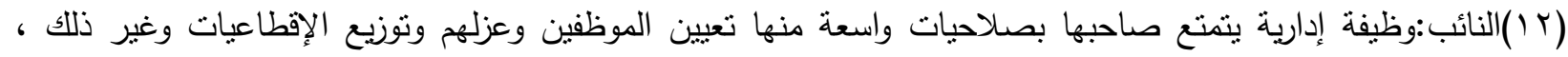

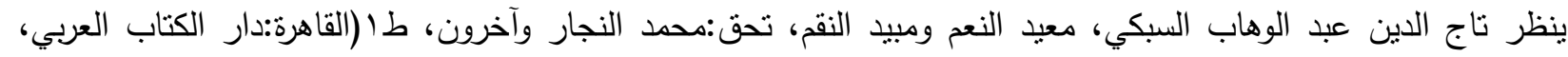

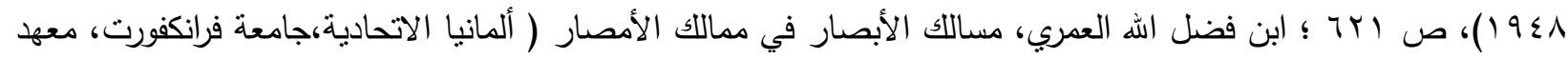

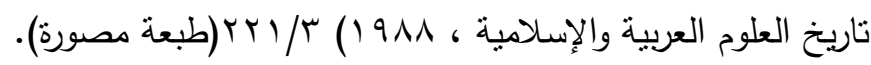

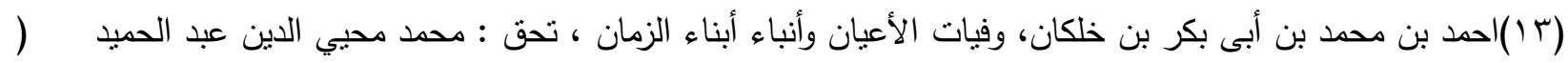

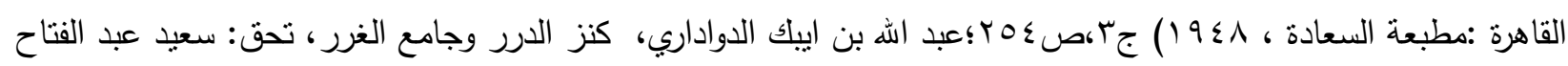

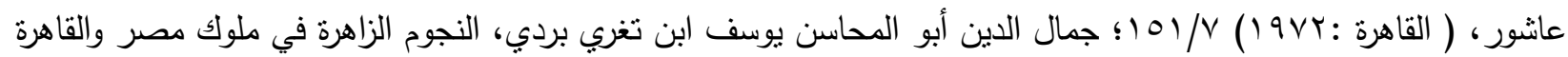

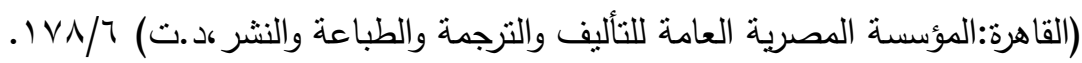
(ع ()ينظر نظير احسان سعداوي،التاريخ الحربي المصري في عهز السلطان صلاح الدين الأيوبي، ( القاهرة: مكتبة النهضة

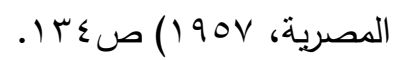

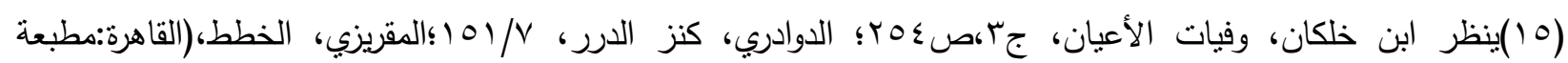

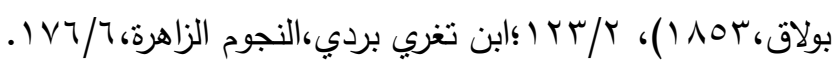

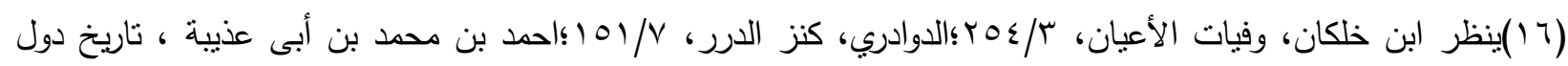

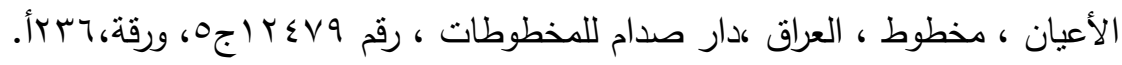




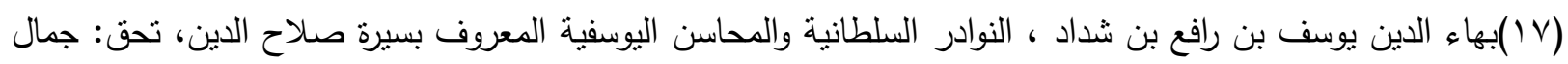

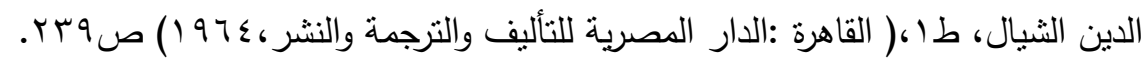
(1) (1)المقريزي، السلوك لمعرفة دول الملوك، تصحيح: محمد مصطفى زيادة، (القاهرة:مطبعة دار الكتب المصرية،

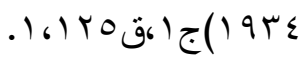

(9 ())الثاد:وظيفة عسكرية مهمة القائم بها مصاحبة جباة الضرائب لتوفير الحماية لهم من تجاوزات المطالبين بها وإرغامهم

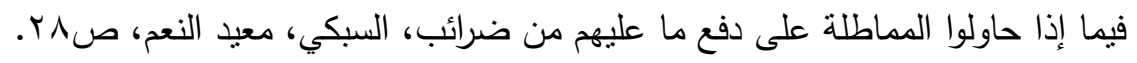

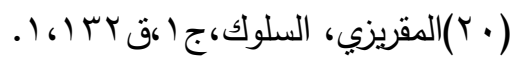

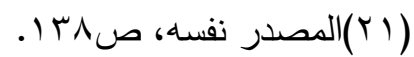

(Yr) (Yمال الدين محمد بن سالم بن واصل، مفرج الكروب في أخبار بني أيوب، تحق: جمال الدين الثبال، (القاهرة :دار

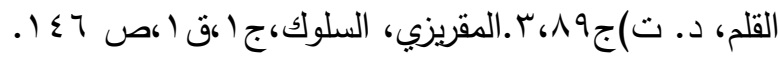

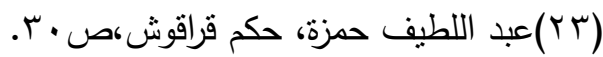

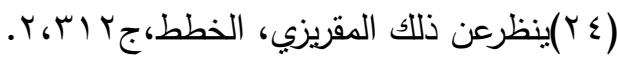

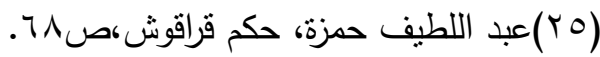

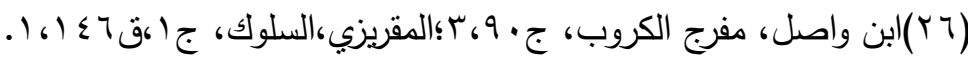

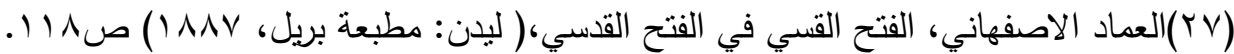
(r^)

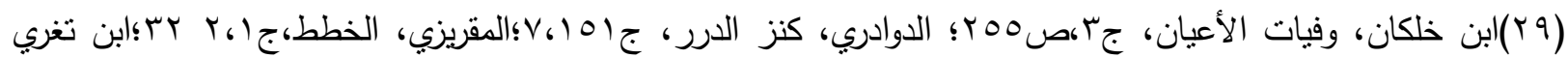

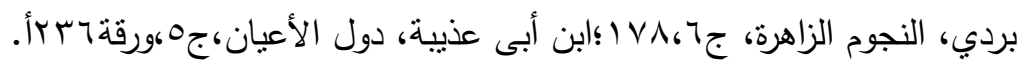

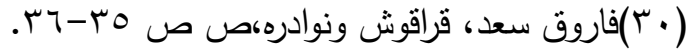

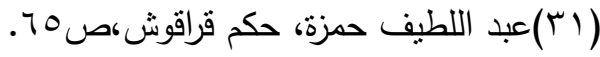

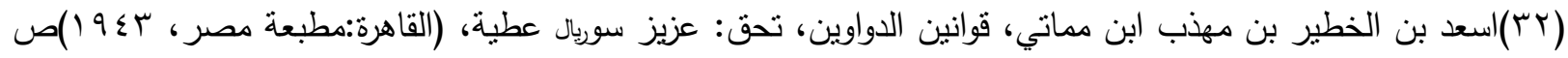

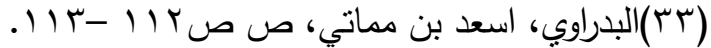

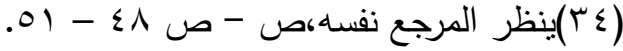

$$
\begin{aligned}
& \text { (T0)عبد اللطيف حمزة، حكم قراقوش،صرك } 7 .
\end{aligned}
$$

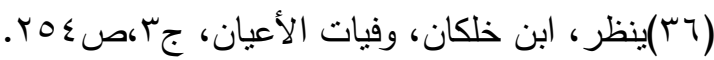

(YV) الجهبذ:هو أحد موظفي ديوان المال وتقع عليه مسؤولية حفظ ما يرد من اموال وتحديد الجهة التي ارسلتها وكتابة الإيصالات التي تتعلق بها. ومن مسئوليته عمل السجلات التي تعرف بالمخازيم وعمل قوائم يعرف بعضها بالروزنمجات

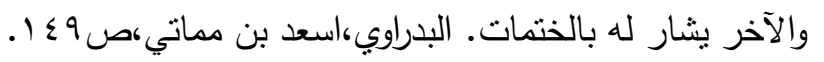

(^^^)المخازيم سجلات تحوي جملة من المعلومات التي تتعلق بالفلاحين وطريقة استغلال الارض كأن تكون مقاسمة اومناصفة أو مثالثة ....الخ، والرسوم المنرتبة عليها وما صرف من بذور . طرخان، إبراهيم علي، النظم الإقطاعية في الثرق

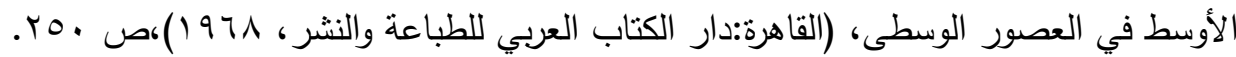
(9) جمال الدين أبو الحسن علي الازدي ابن ظافر بدائع البدائه، تحق: محمد أبو الفضل إبراهيم، ( القاهرة: مكتبة الانجلو مصرية، (1970)ص (191) 


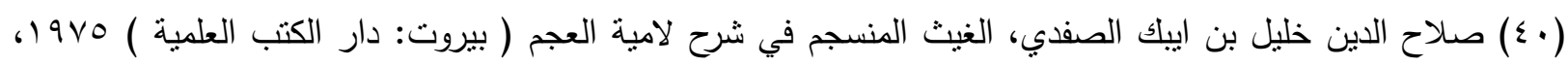
جr|صAr

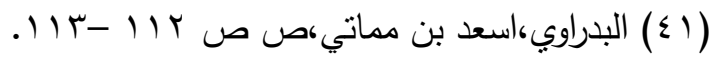

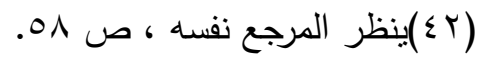

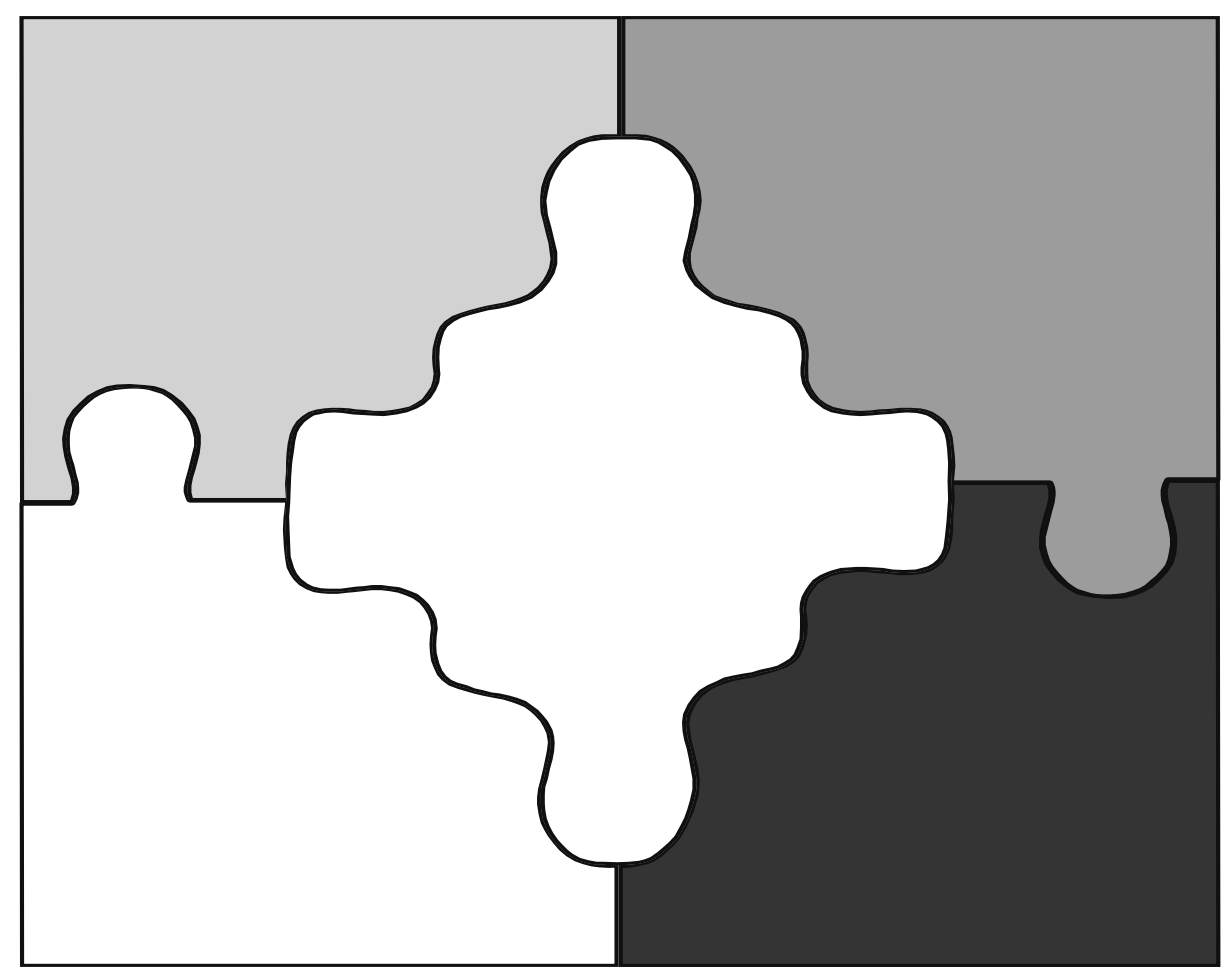

